\title{
O MEIO FÍSICO DE FEIRA DE SANTANA E O DIREITO À CIDADE
}

\author{
Débora Pinto Lafaiete ${ }^{1}$; Gracinete Souza Bastos ${ }^{2}$ \\ 1. Bolsista PIBIC/CNPq, Graduanda em Engenharia civil, Universidade Estadual de Feira de Santana, e-mail: \\ debora_lafaiete@ hotmail.com \\ 2. Orientadora, Departamento de Exatas, Universidade Estadual de Feira de Santana, e-mail: gracinet@uefs.br
}

PALAVRAS-CHAVE: meio físico, planejamento urbano, direito à cidade.

\section{INTRODUÇÃO}

A análise do meio físico (relevo, geologia, água e clima) representa uma das principais bases para o estudo do processo de urbanização. Como se configura esse meio físico, se há planejamento de determinadas áreas urbanas, quais são os limites e as potencialidades relacionadas ao seu uso, são algumas questões que se pode explorar a partir da análise do meio físico.

As análises, sobre o meio físico e os processos de urbanização, existentes, dialogam diretamente com o estudo sobre o direito à cidade. Há limites em discorrermos sobre como os seres humanos organizam a vida nas cidades e as problemáticas envolvidas, sem a devida compreensão dos aspectos de urbanização de cada região.

Harvey (2014), um grande estudioso na área, inicia as discussões sobre o direito à cidade, demarcando duas grandes posições; uma refere-se à defesa que o direito a cidade é mais do que um direito/acesso individual, sendo assim, um direito coletivo, visto que, através do exercício do poder coletivo sobre os processos de urbanização, se faz possível reinventar e recriar o meio em que se vive; outra situa o estudo (direito à cidade) no atual modelo de sociedade, o capitalismo. Sendo esse último a base necessária para as análises contemporâneas.

Destarte, diante desses elementos gerais, o atual plano de trabalho "O Meio físico de Feira de Santana e o Direito à cidade" reafirma sua importância, visto que se objetiva relacionar esses aspectos (meio físico e direito à cidade) através dos estudos previamente realizados. Esses estudos tratam da realidade do meio físico do município de Feira de Santana, mais especificamente, seus 8 distritos (Bonfim de Feira, Ipuaçu, Jaguara, Maria Quitéria, Tiquaruçu, Humildes, Matinha e Jaiba), e foram realizados através dos antigos planos de trabalho de iniciação científica, vinculados ao projeto "Integração de Dados sobre os Aspectos do Meio Físico do Município de Feira de Santana, Ba". Esses materiais possibilitam realizar um diagnóstico dessa relação com base no município de Feira de Santana, apontando seus limites e suas potencialidades.

\section{MATERIAIS E MÉTODOS}

A realização do projeto iniciou-se com uma revisão bibliográfica, com o objetivo de realizar uma fundamentação teórica dos elementos (temas e assuntos) que envolvem o plano de trabalho como, por exemplo, os aspectos do meio físico, planejamento urbano, direito a cidade. Ocorreu, também, o levantamento das informações pré-existentes, por meio de análises das pesquisas realizadas anteriormente, 
através do relatório final dos planos de trabalho de iniciação científica, vinculados ao projeto "Integração de Dados sobre os Aspectos do Meio Físico do Município de Feira de Santana, BA". Após o levantamento desses elementos partiu-se para a análise da relação do meio físico, do município de Feira de Santana, com os estudos do direito à cidade fazendo também uma análise do histórico da urbanização da cidade.

\section{RESULTADOS E DISCUSSÕES}

A história de ocupação da cidade de Feira de Santana foi marcada por um desenvolvimento comercial, devido à economia pecuária da região próxima, resultando na organização de uma feira de gado, assim como um comércio paralelo de alimentos, necessário à sobrevivência da população. Os aspectos do meio físico do município são a base para compreender a fixação da população nesse espaço, na medida em que, o tipo de relevo plano assim como uma hidrografia abundante em rios, fontes e lagoas, possibilitavam que os boiadeiros, que transportavam o gado do interior ao porto de Cachoeira, pousassem no município. Esse processo de ocupação se expandiu ao longo dos anos, mas não se diferenciou da maioria dos municípios brasileiros em que suas ocupações ocorreram de forma espontânea e desordenada.

$\mathrm{Na}$ análise dos resultados dos planos de pesquisa anteriores, observou-se um padrão referente à falta de uma base de dados dos elementos que retratam o meio físico. Esse elemento é contraditório - quando se pensa a organização planejada da cidade - na medida em que a análise do meio físico é o ponto de partida para se pensar o planejamento urbano de determinado lugar.

Na tabela abaixo, segue uma relação do meio físico com o debate do direito à cidade, extraídos das pesquisas anteriores.

Tabela 1. Aspectos do meio físico dos distritos do município de Feira de Santana

\begin{tabular}{|c|c|c|}
\hline Distrito & $\begin{array}{c}\text { Características do meio } \\
\text { físico }\end{array}$ & Limites e Possibilidades \\
\hline $\begin{array}{l}\text { G. João } \\
\text { Durval }\end{array}$ & Solo pouco espesso & $\begin{array}{l}\text { Suscetíveis à saturação dos horizontes } \\
\text { superiores, facilitando a progressão de } \\
\text { enxurradas. }\end{array}$ \\
\hline $\begin{array}{l}\text { Bonfim de } \\
\text { Feira }\end{array}$ & $\begin{array}{l}\text { Presença de serras, o solo } \\
\text { pouco espesso com } \\
\text { afloramentos de rocha }\end{array}$ & $\begin{array}{l}\text { Dificulta o processo de Urbanização } \\
\text { devido à presença de encostas. O solo } \\
\text { pouco espesso e os afloramentos de } \\
\text { rocha podem proporcionar problema para } \\
\text { as instalações de água e esgoto }\end{array}$ \\
\hline Jaíba & $\begin{array}{l}\text { Relevo plano; } \\
\text { predominância de solo } \\
\text { arenoso; }\end{array}$ & $\begin{array}{l}\text { Relevo plano pode ocasionar inundações } \\
\text { e também um problema para as } \\
\text { instalações de água e esgoto; o tipo de } \\
\text { solo aumenta a exploração para a } \\
\text { construção civil. }\end{array}$ \\
\hline $\begin{array}{l}\text { Maria } \\
\text { Quitéria }\end{array}$ & Relevo plano & $\begin{array}{l}\text { Relevo plano pode ocasionar inundações } \\
\text { e também um problema para as } \\
\text { instalações de água e esgoto. }\end{array}$ \\
\hline $\begin{array}{l}\text { Matinha } \\
\text { dos Pretos }\end{array}$ & Solo pouco espesso & $\begin{array}{l}\text { Suscetíveis à saturação dos horizontes } \\
\text { superiores, facilitando a progressão de } \\
\text { enxurradas. O solo pouco espesso e os } \\
\text { podem proporcionar problema para as } \\
\text { instalações de água e esgoto }\end{array}$ \\
\hline
\end{tabular}




\begin{tabular}{l|ll} 
Jaguara & Solo pouco espesso & $\begin{array}{l}\text { Suscetíveis à saturação dos horizontes } \\
\text { superiores, facilitando a progressão de } \\
\text { enxurradas. O solo pouco espesso e os } \\
\text { pode proporcionar problema para as } \\
\text { instalações de água e esgoto } \\
\text { Tiquaruçu }\end{array}$ \\
Humildes & $\begin{array}{l}\text { Exploração para a construção civil } \\
\text { arenoso e argiloso } \\
\text { Fora do polígono das } \\
\text { secas; Predominância de } \\
\text { solo arenoso; }\end{array}$ & $\begin{array}{l}\text { Extração de areia/ exploração para a } \\
\text { construção civil }\end{array}$ \\
\hline
\end{tabular}

Fonte: Planos de pesquisa vinculados ao projeto "Integração de Dados sobre os Aspectos do Meio Físico do Município de Feira de Santana".

Tais elementos do meio físico, se não servirem de base para se pensar uma ocupação do espaço, pode resultar em problemas diversos como, por exemplo, ocupações irregulares próximas às encostas, a possibilidade de alagamentos nas regiões de habitação devido ao meio propício às enxurradas e alagamentos, a extração inadequada dos recursos naturais como o caso da areia que, sem o planejamento adequado, podem acarretar em desmatamento, assoreamento de rios e erosões e, como explicitado acima, devido à característica do solo, dificuldades de instalações de rede de água e esgoto.

A situação atual da hidrografia da região reforça esses elementos. O município, que antes era abundante em rios, lagoas, hoje apresenta um quadro de poluição e um intenso processo de assoreamento, devido à utilização das lagoas para depósito de lixo e a fixação aos redores dos rios, contribuindo para a destruição da mata ciliar. Atualmente, de acordo com os dados do Instituto Brasileiro de Geografia e Estatística (IBGE), apenas 59,7\% dos domicílios do município apresentam esgotamento sanitário adequado, destacando a manutenção do descaso e a falta de prioridade do Poder público de garantir uma infraestrutura adequada para as demais regiões e, consequentemente, reproduzindo a degradação ambiental.

Um panorama geral demonstra que as lagoas situadas no perímetro urbano, foram atingidas pelos despejos de efluentes domésticos e aterramentos, enquanto que as lagoas localizadas na zona rural sofreram impactos devido à modificação da vegetação, extração de insumos para a área da construção civil e construção de estradas. (NETO et al., s/d). Atualmente, as lagoas são protegidas pelo Código Municipal do Meio Ambiente e, projetos de recuperação das lagoas têm sido apresentados como uma forma de tornar a cidade mais sustentável.

Nos planos de trabalho analisados, apenas na análise do distrito de Humildes, Bonfim de Feira e Tiquaruçu, apareceram elementos sobre a organização social da cidade, dificultando a construção de um panorama completo. No distrito de Humildes, $50 \%$ da população reside em áreas urbanas, no qual se encontra a presença de escolas, postos de saúde, cartório, postos policiais, assim como, parte das indústrias, com a implantação do Centro Industrial Subaé (CIS) em 1970, são localizadas aos seus arredores; em Bonfim de Feira, o núcleo urbano apresenta um comércio restrito, assim como três escolas públicas e uma biblioteca municipal, além de oito escolas da $1^{\mathrm{a}}$ à $4^{\mathrm{a}}$ série na zona rural; e o distrito de Tiquaruçu apresenta traços de urbanização, os povoados estão crescendo de maneira contínua, o mesmo apresenta escolas, postos de saúde, agencia dos correios, posto policial.

Esses elementos retratam o espaço em sua forma, mas não, por assim dizer, em seu conteúdo; isso significa que a quantidade de escolas, postos de saúde, etc., por si só, não garantem um debate profundo sobre o direito à cidade, pois apresenta apenas uma 
dimensão de uma análise social que precisa considerar, também, as condições postas para o acesso desses espaços. Em outras palavras, faz-se necessário analisar se a "quantidade" é suficiente, diante da demanda social, se o crescimento dos povoados está ocorrendo de forma regular, como ocorre a mobilidade urbana-rural, as crianças e os jovens tem a possibilidade de acessar a educação ou precisam trabalhar, diante da vulnerabilidade econômica imposta, entre outras coisas.

Nesse ínterim, percebe-se que tais discussões formam um corpo que nos serve de base para avançarmos nas discussões sobre a organização da cidade de Feira de Santana, assim como, o direito de acesso ao espaço e os elementos que o compõe - escolas, hospitais, praças, infraestrutura/saneamento básico, moradia, mobilidade.

\section{CONCLUSÃO}

A partir dessa breve discussão, tornou-se possível identificar a importância da análise do meio físico e sua relação com o aspecto social na organização dos espaços, ao mesmo tempo, evidencia a impossibilidade de pensar o espaço/meio físico sem os aspectos sociais. Contudo, é necessário compreender que o meio físico se coloca enquanto ponto de partida de debates sobre o direito à cidade que são muito mais profundos, sobretudo, quando pensamos nos interesses existentes nesse modelo de sociedade.

Percebe-se que o objetivo inicial da pesquisa não foi completamente efetivado, visto que as bases (planos de trabalho anteriores) que foram pensadas para realizar um diagnóstico da relação do meio físico e o direito à cidade de Feira de Santana, foram insuficientes. Além disso, o recorte do objeto ficou muito amplo quando comparamos ao tempo da pesquisa. No entanto, foi possível construir um panorama geral sobre como os componentes, saúde, condições de moradia e trabalho, educação, assim como as condições de acesso, estão colocados para a população do município de Feira de Santana, desenhando, no cotidiano, um cenário de desigualdade, segregação e espoliação urbana; o que nos permite problematizar sobre como as leis que descrevem sobre o direito à cidade se expressam na prática, ao mesmo tempo em que nos coloca a exigência de pensar uma alternativa coletiva para essa situação geral.

$\mathrm{Na}$ busca de aprofundar sobre esse tema, no próximo momento da pesquisa o enfoque será dado ao distrito de Bonfim de Feira, no qual será possível traçar um panorama mais aprofundado sobre o distrito.

\section{REFERÊNCIAS}

HARVEY, David. 2014. Cidades rebeldes: do direito à cidade à revolução urbana/ David Harvey. -São Paulo: Martins Fontes - selo Martins.

IBGE. Instituto Brasileiro de Geografia e Estatística. Disponível em: < https://cidades.ibge.gov.br/brasil/ba/feira-de-santana/panorama>. Acesso em $22 \mathrm{de}$ agosto de 2018.

NETO, J.S.C, et al. Alterações na dinâmica do conjunto de lagoas em Feira de Santana - BA, a partir de modificações antrópicas. - Universidade Estadual de Feira de Santana, $\mathrm{s} / \mathrm{d}$. 